\title{
Improvement of Yield Strength-Transition Temperature Balance by Microstructural Refinement
}

\author{
Akihiko TAKAHASHI and Makio IINO ${ }^{1)}$ \\ Yawata R \& D Laboratory, Nippon Steel Corporation, Tobihatacho, Tobata, Kitakyushu, Fukuoka-ken, 804 Japan. \\ 1) Formerly Nippon Steel Corporation. Now at Yamaguchi University, Tokiwadai, Ube, Yamaguchi-ken, 755 Japan.
}

(Received on June 21, 1995; accepted in final form on September 25, 1995)

\begin{abstract}
Grain-refinement simultaneously increases yield strength and toughness while the strengthening without the grain-refinement still deteriorates the toughness. It is worth assessing how the strengthening relates to the toughness to strengthen steels most appropriately. In this study, different mechanisms for strengthening are compared with respect to the relationship between yield strength and ductile-brittle fracture transition temperature. Considered are the grain-refinement by solute copper or thermo-mechanical control process (TMCP), the precipitation-hardening by copper, and the bainite-transformation hardening with alloying elements such as boron, molybdenum, and nickel. The transition temperature rises with strengthening by the precipitation-hardening and the transformation-hardening. In this case, the relationship is approximately linear with the gradient of $0.46^{\circ} \mathrm{C} / \mathrm{MPa}$. In contrast, the transition temperature lowers in the case of the strengthening by the grain-refinement achieved by the solute copper and the TMCP. This study aims at relating the yield strength to the transition temperature on a dislocation crack model of brittle fracture. Considering the energy balance for brittle crack initiation and the temperature dependence of the friction stress for the Hall-Petch relationship gives the linear lowering of transition temperature with increasing yield strength by grain-refinement, of which gradient is estimated at approximately $0.80^{\circ} \mathrm{C} / \mathrm{MPa}$. The comparison of experimental results with this relationship indicates that the strengthening by solute copper effectively utilizes the grain-refinement.
\end{abstract}

KEY WORDS: yield strength; ductile-brittle fracture transition temperature; grain-refinement; dislocation crack model.

\section{Introduction}

There are a number of strengthening mechanisms to steels, including grain-refinement, precipitation-hardening, solid-solution hardening, and transformationhardening. With respect to the grain-refinement, the lower yield strength of iron follows the relationship:

$$
\sigma_{\text {lys }}=\sigma_{0}+k d^{-1 / 2}
$$

where $\sigma_{\text {lys }}$ is the lower yield strength, $\sigma_{0}$ and $k$ are constants, and $d$ is the average grain diameter. This law is known as the Hall-Petch relationship. ${ }^{1)}$ In addition, ductile-brittle transition, which is one of the most serious concerns of materials design, is also a function of the grain diameter. Petch advanced his discussion on the relationship between fracture stress and grain diameter and studied the grain diameter dependence of the ductile-brittle transition temperature ${ }^{2)}$ :

$$
\beta T_{\mathrm{c}}=B-\ln d^{-1 / 2}
$$

where $T_{\mathrm{c}}$ is the ductile-brittle transition temperature and $\beta, B$ are constants.

Since the grain-refinement is the only method to strengthen and simultaneously toughen steels, it has been very important from the viewpoint of manufacturing structural steels having high fracture toughness. We have reported that the $\mathrm{Cu}$ addition and the thermomechanical control process (TMCP) composed of heavy reduction rolling followed by rapid cooling are effective tools for grain-refinement to strengthen and toughen low Mn containing steels in an attempt to obtain sour service line pipe steels. ${ }^{3,4)}$

The yield strength and the transition temperature are similarly functions of grain diameter. Consequently, the transition temperature can be related to the yield strength through the grain diameter. In the present study the slope of the lowering transition temperature as strengthening with grain-refinement is estimated and compared with that of the rising transition temperature as strengthening with other mechanisms like precipitation-hardening and bainite transformation. After that, the yield strengthtransition temperature relationship achieved by grainrefinement alone is formulated from a dislocation crack model, with which the improvement of yield strengthtransition temperature balance obtained by the TMCP or $\mathrm{Cu}$ addition is evaluated in view of how it obeys the ideal improvement by grain-refinement alone. 
Table 2. Hot rolling condition of $\mathrm{Cu}$ containing steels.

\begin{tabular}{ccccccc}
\hline $\begin{array}{c}\text { Heating } \\
\left({ }^{\circ} \mathrm{C} 1 \mathrm{~h}\right)\end{array}$ & $\begin{array}{c}\text { Entry thickness } \\
(\mathrm{mm})\end{array}$ & $\begin{array}{c}\text { Rolling start temp. } \\
\left({ }^{\circ} \mathrm{C}\right)\end{array}$ & $\begin{array}{c}\text { Exit thickness } \\
(\mathrm{mm})\end{array}$ & $\begin{array}{c}\text { Rolling finish temp. } \\
\left({ }^{\circ} \mathrm{C}\right)\end{array}$ & $\begin{array}{c}\text { Cooling finish temp. } \\
\left({ }^{\circ} \mathrm{C}\right)\end{array}$ & $\begin{array}{c}\text { Cooling rate } \\
\left({ }^{\circ} \mathrm{C} / \mathrm{s}\right)\end{array}$ \\
\hline 1050 & 60.0 & 850 & 12.5 & 825 & R.T. & 55 \\
\hline
\end{tabular}

Table 1. Chemical composition of tested steels. (mass\%, *: ppm)

\begin{tabular}{|c|c|c|c|c|c|c|c|c|c|c|c|c|c|}
\hline Code & C & $\mathrm{Si}$ & $\mathrm{Mn}$ & $\mathbf{p *}$ & $\mathrm{S*}$ & $\mathrm{Ni}$ & $\mathrm{Cu}$ & Mo & Al & $\mathrm{Nb}$ & $\mathbf{T i}$ & B & $\mathbf{N}^{*}$ \\
\hline $\mathrm{Cu}$ & 0.05 & 0.2 & 0.2 & 30 & 8 & $\cdots$ & $\begin{array}{l}1.0 \\
1.2 \\
1.4 \\
1.7 \\
2.1 \\
3.1\end{array}$ & $\cdots$ & 0.03 & 0.04 & 0.02 & $\cdots$ & 16 \\
\hline M4 & 0.08 & 0.2 & 0.5 & 90 & 15 & -.. & $\ldots$ & $\cdots$ & $\cdots$ & 0.02 & 0.04 & $\cdots$ & 30 \\
\hline MI & 0.11 & 0.2 & 0.5 & 20 & 5 & $\cdots$ & $\cdots$ & $\ldots$ & 0.02 & 0.04 & ... & $|0.0010|$ & 19 \\
\hline M2 & 0.10 & 0.2 & 0.5 & 20 & 6 & $\ldots$ & $\cdots$ & 0.3 & 0.02 & 0.04 & $\cdots$ & $\cdots$ & 20 \\
\hline G2 & 0.07 & 0.3 & 0.9 & 60 & 11 & 0.4 & $\cdots$ & $\cdots$ & 0.02 & 0.02 & 0.02 & $\cdots$ & 20 \\
\hline
\end{tabular}

Table 3. Precipitation treatment of $\mathrm{Cu}$ to 1.7 mass $\%$ and 2.1 mass $\% \mathrm{Cu}$ containing steels.

\begin{tabular}{cl}
\hline Aging code & Aging temperature and time \\
\hline $\mathrm{A} 1$ & $450^{\circ} \mathrm{C}, 1800 \mathrm{~s}(30 \mathrm{~min}) \mathrm{A} . \mathrm{C}$. \\
$\mathrm{A} 2$ & $550^{\circ} \mathrm{C}, 1800 \mathrm{~s}(30 \mathrm{~min})$ A.C. \\
\hline
\end{tabular}

Table 4. TMCP variables for the heavy reduction and/or the rapid cooling to steel M4. Pass schedule P4 employs the heavy reduction and cooling rates marked with square are rapid cooling.

\begin{tabular}{|c|c|c|c|c|c|c|}
\hline Condition & $\begin{array}{c}\text { Heating } \\
{ }^{\circ} \mathrm{C} \\
1 \mathrm{~h}\end{array}$ & $\begin{array}{l}\text { Rolling } \\
\text { start } \\
\text { temp. } \\
{ }^{\circ} \mathrm{C}\end{array}$ & $\begin{array}{l}\text { Pass } \\
\text { schedule }\end{array}$ & $\begin{array}{l}\text { Rolling } \\
\text { finish } \\
\text { temp. } \\
{ }^{\circ} \mathrm{C}\end{array}$ & $\begin{array}{l}\text { Cooling } \\
\text { finish } \\
\text { temp. } \\
{ }^{\circ} \mathrm{C}\end{array}$ & $\begin{array}{l}\text { Cooling } \\
\text { rate } \\
{ }^{\circ} \mathrm{C} / \mathrm{s}\end{array}$ \\
\hline Base & 1250 & 870 & $\mathrm{P3}$ & 809 & 400 & 19 \\
\hline Heavy reduction & 1250 & 870 & $\mathrm{P4}$ & 838 & 400 & 21 \\
\hline Rapid cooling & 1250 & 870 & $\mathrm{P3}$ & 814 & 250 & 94 \\
\hline H.R. \& R.C. & 1250 & 870 & $\mathrm{P4}$ & 850 & 350 & 83 \\
\hline
\end{tabular}

$$
\begin{aligned}
& 1250^{\circ} \mathrm{C} \vee 870^{\circ} \mathrm{C} \quad \checkmark 850^{\circ} \mathrm{C}
\end{aligned}
$$

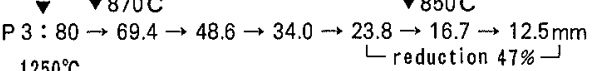

$$
\begin{aligned}
& 1250^{\circ} \mathrm{C} \vee 870^{\circ} \mathrm{C} \quad \nabla 850^{\circ} \mathrm{C} \\
& \text { P } 4: 80 \rightarrow 53.4 \rightarrow 32.1 \rightarrow 19.2 \rightarrow 12.5 \mathrm{~mm} \\
& \text { Lreduction } 61 \%-
\end{aligned}
$$

\begin{tabular}{|c|c|c|c|c|c|c|c|}
\hline Steel & $\begin{array}{l}\text { Rolling } \\
\text { code }\end{array}$ & $\begin{array}{l}\text { Heating } \\
{ }^{\circ} \mathrm{C} \\
1 \mathrm{~h}\end{array}$ & $\begin{array}{l}\text { Rolling } \\
\text { start } \\
\text { temp. } \\
{ }^{\circ} \mathrm{C}\end{array}$ & $\begin{array}{c}\text { Pass } \\
\text { schedule }\end{array}$ & $\begin{array}{l}\text { Rolling } \\
\text { finish } \\
\text { temp. } \\
{ }^{\circ} \mathrm{C}\end{array}$ & $\begin{array}{l}\text { Cooling } \\
\text { finish } \\
\text { temp. } \\
{ }^{\circ} \mathrm{C}\end{array}$ & $\begin{array}{l}\text { Cooling } \\
\text { rate } \\
{ }^{\circ} \mathrm{C} / \mathrm{s}\end{array}$ \\
\hline \multirow{5}{*}{ M 1} & M 1-1 & 1250 & 900 & P 5 & 875 & 281 & 30 \\
\hline & $M 1-2$ & 1100 & 900 & $P 5$ & 885 & 315 & 29 \\
\hline & M 1-3 & 950 & 900 & $P 5$ & 871 & 249 & 31 \\
\hline & $M 1-4$ & 1250 & 900 & $\mathrm{P} 5$ & 886 & R.T. & 50 \\
\hline & $M 1-5$ & 1100 & 900 & $P 5$ & 878 & 579 & 43 \\
\hline \multirow{5}{*}{ M 2} & M 2-1 & 1250 & 900. & $\mathrm{P} 5$ & 888 & 313 & 29 \\
\hline & $\mathrm{M} 2-2$ & 1100 & 900 & $\mathrm{P} 5$ & 868 & 462 & 20 \\
\hline & $\mathrm{M} 2-3$ & 950 & 900 & P 5 & 867 & 338 & 27 \\
\hline & $M 2-4$ & 1250 & 900 & P 5 & 905 & R.T. & 50 \\
\hline & $M 2-5$ & 1100 & 900 & P 5 & 868 & 513 & 51 \\
\hline & $\begin{array}{c}1250^{\circ} \mathrm{C} \\
\nabla 1100 \\
950\end{array}$ & $\nabla 900^{\circ} \mathrm{C}$ & \multirow{2}{*}{\multicolumn{2}{|c|}{$\nabla 850^{\circ} \mathrm{C}$}} & & & \\
\hline $\mathrm{P}$ & 60 & $\rightarrow$ & & & $12.5 \mathrm{~mm}$ & & \\
\hline
\end{tabular}

Table 5. Hot rolling conditions for steel M1 and steel M2.

\begin{tabular}{|c|c|c|c|c|c|c|c|}
\hline Steel & $\begin{array}{l}\text { Rolling } \\
\text { code }\end{array}$ & $\begin{array}{l}\text { Heating } \\
{ }^{\circ} \mathrm{C} \\
1 \mathrm{~h}\end{array}$ & $\begin{array}{l}\text { Rolling } \\
\text { start } \\
\text { temp. } \\
{ }^{\circ} \mathrm{C}\end{array}$ & $\begin{array}{l}\text { Pass } \\
\text { schedule }\end{array}$ & $\begin{array}{l}\text { Rolling } \\
\text { finish } \\
\text { temp. } \\
{ }^{\circ} \mathrm{C}\end{array}$ & $\begin{array}{c}\text { Cooling } \\
\text { finish } \\
\text { temp. } \\
{ }^{\circ} \mathrm{C} .\end{array}$ & $\begin{array}{l}\text { Cooling } \\
\text { rate } \\
{ }^{\circ} \mathrm{C} / \mathrm{s}\end{array}$ \\
\hline \multirow{6}{*}{ G 2} & G $2-1$ & 1150 & 830 & P 6 & 789 & R.T. & 51 \\
\hline & $G 2-2$ & 1150 & 830 & P 6 & 818 & 465 & 60 \\
\hline & $G 2-3$ & 1150 & 830 & P 6 & 823 & 457 & 31 \\
\hline & $G 2-4$ & 950 & 830 & P 6 & 792 & R.T. & 51 \\
\hline & $\mathrm{G} 2-5$ & 950 & 830 & P 6 & 800 & 607 & 33 \\
\hline & $G 2-6$ & 950 & 830 & P 6 & 809 & 413 & 33 \\
\hline \multicolumn{8}{|c|}{$1150^{\circ} \mathrm{C}$} \\
\hline $\mathrm{P}$ & : 60 & $\rightarrow \quad 40$ & $\rightarrow$ & $2.5 \mathrm{~mm}$ & & & \\
\hline
\end{tabular}

Table 6. Hot rolling conditions for steel $\mathrm{G} 2$.

\section{Experimental}

Several casts were prepared to give different chemical composition as listed in Table 1. The purposes of changing the composition are as follows.

Steels $\mathrm{Cu}$ : The addition of $\mathrm{Cu}$ varies from 1.0 to 3.1 mass $\%$ in order to grain-refine the steels containing low $\mathrm{Mn}$ of 0.2 mass $\%$ by solute $\mathrm{Cu}$, or to precipitationharden during cooling after hot rolling by the excess $\mathrm{Cu}$ which is more than super saturated in ferrite. Table 2 shows the rolling condition of steels $\mathrm{Cu}$. Regarding the 1.7 and 2.1 mass $\% \mathrm{Cu}$ added steels, aging was also carried out to strengthen by precipitation-hardening of $\mathrm{Cu}$ during heat treatment as shown in Table 3.

Steel M4: This steel containing $0.5 \mathrm{mass} \% \mathrm{Mn}$ with $\mathrm{Nb}$ and $\mathrm{Ti}$ is rolled with the TMCP which consists of the heavy reduction of $60 \%$ in final two passes and the rapid cooling rate of $80^{\circ} \mathrm{C} / \mathrm{s}$ in order to estimate the effect of the process on grain-refinement. The TMCP variables for the heavy reduction and rapid cooling is compared with a base condition in Table 4.

Steel M1: Boron is added, expecting the bainite transformation to be a mechanism of strengthening the low Mn containing steel.

Steels M2, G2: Similarly molybdenum and nickel are respectively added as an alloying element for strengthening.

Rolling schedules provide the differences of yield strength and toughness about steels M1, M2, and G2 as shown in Tables 5 and 6 , where the effect of alloying elements are estimated.

After having rolled and precipitation-hardened the materials as above mentioned, the tensile test using the JIS A4 type specimen and the Charpy impact test were performed.

\section{Results}

The ductile-brittle transition temperature measured in the Charpy impact test is plotted versus the yield 


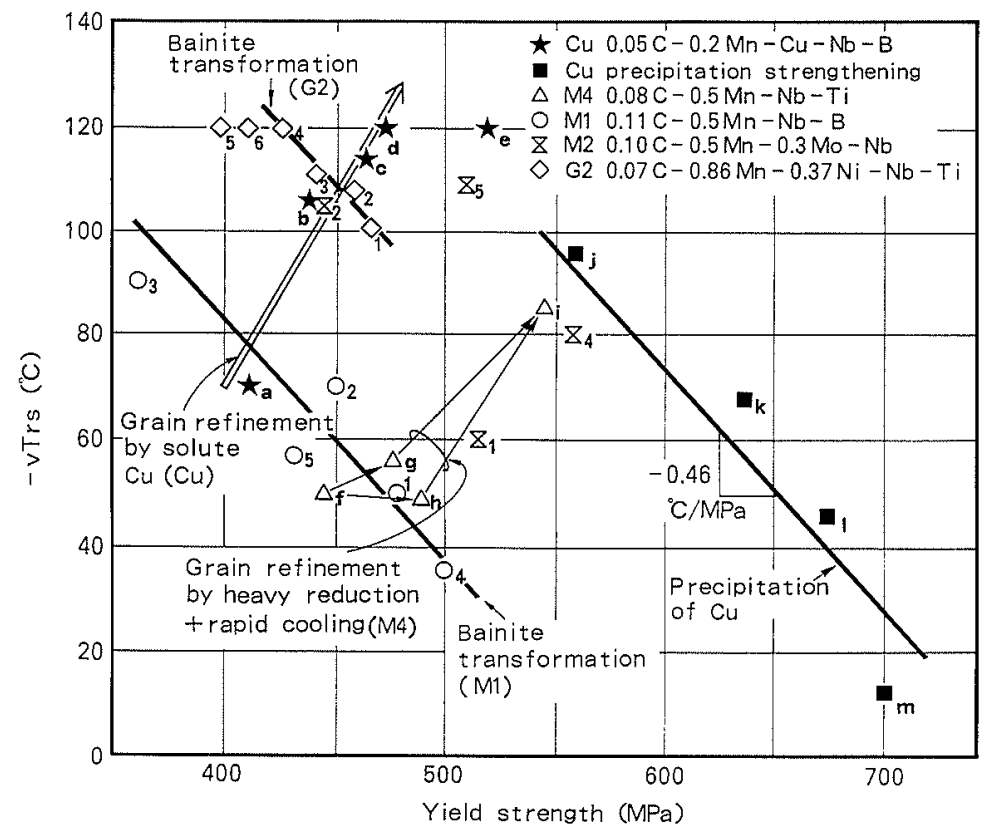

Fig. 1.

Relationship between yield strength and Charpy transition temperature for various strengthening mechanisms. The subscript number with each mark of steels $\mathrm{M} 1, \mathrm{M} 2$, and $\mathrm{G} 2$ shows the rolling code. (For example, $\mathrm{O}_{1}$ means the steel $\mathrm{M} 1$ rolled with the rolling code M1-1.) For steels $\mathrm{Cu}(\star)$, the $\mathrm{Cu}$ content is (a) 1.0 , (b) 1.2 , (c) 1.4 , (d) 1.7 , and (e) 2.1 mass $\%$ and for steel M4 $(\triangle)$, the TMCP condition is (f) base condition, (g) rapid cooling, (h) heavy reduction, (i) and heavy reduction followed by rapid cooling. The condition of precipitation ( $\mathbf{(})$ is $(\mathrm{j}) 1.7$ mass $\% \mathrm{Cu}$, aged at $450^{\circ} \mathrm{C}$, (k) 2.1 mass $\% \mathrm{Cu}$, aged at $450^{\circ} \mathrm{C}$, (l) 1.7 mass $\% \mathrm{Cu}$, aged at $550{ }^{\circ} \mathrm{C}$, and (m) 3.1 mass $\%$ $\mathrm{Cu}$, as rolled.

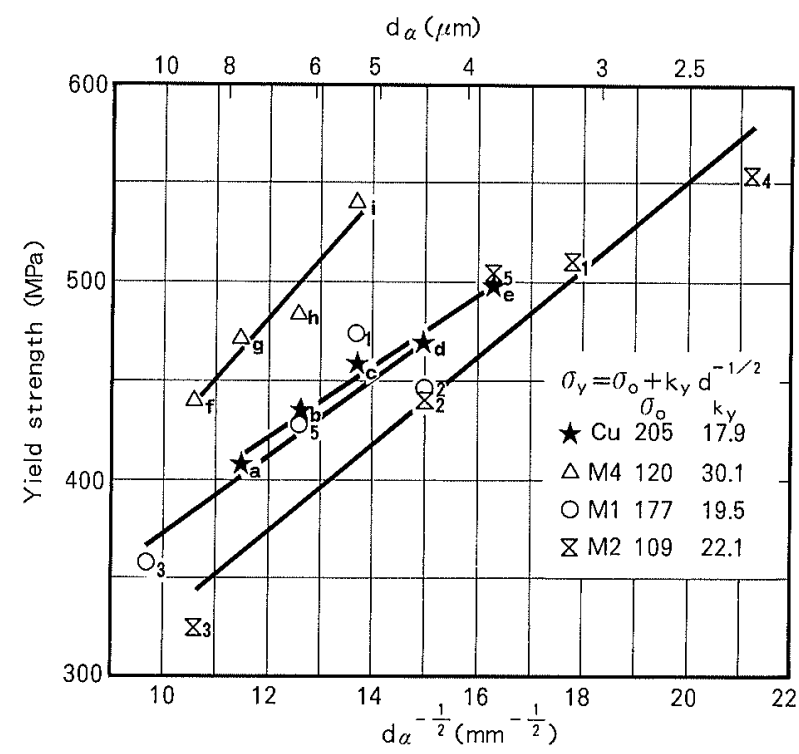

Fig. 2. Hall-Petch relationship obtained for considered strengthening mechanisms. $d_{\alpha}$ is ferrite grain diameter. For steels $\mathrm{Cu}(\star)$, the $\mathrm{Cu}$ content is (a) 1.0 , (b) 1.2 , (c) 1.4, (d) 1.7, and (e) 2.1 mass $\%$ and for steel M4 $(\triangle)$, the TMCP condition is (f) base condition, (g) rapid cooling, (h) heavy reduction, (i) and heavy reduction followed by rapid cooling.

strength for the tested materials in Fig. 1. Here pay attention to the vertical axis where the transition temperature is in negative sign, accordingly the fracture toughness becomes better going up along the axis. The yield strength-transition temperature relationship is divided into two groups. One is the improving toughness in spite of strengthening, the $\mathrm{Cu}$ addition up to 1.7 mass\% $(\mathrm{Cu})$ and the TMCP (M4) being classified into this group. The other is the deteriorating toughness as strengthening, the precipitation-hardening of $\mathrm{Cu}$ and the bainite transformation (M1, M2, G2) being classified into this group. Another remarkable result is that the transition temperature rises approximately with the gradient of $0.46^{\circ} \mathrm{C} / \mathrm{MPa}$ through strengthening by the precipitation-hardening and the transformation-hardening.

The influence of $\mathrm{Cu}$ on yield strength and transition temperature is described in detail in the previous work. ${ }^{3)}$ The $\mathrm{Cu}$ addition up to 1.7 mass $\%$ simultaneously increases the yield strength and lowers the transition temperature. This effect of $\mathrm{Cu}$ is attributable to grainrefinement. However, the $\mathrm{Cu}$ addition over 2.0 mass $\%$ substantially raises the transition temperature with increasing the yield strength. The adverse effect is attributable to the precipitation of $\mathrm{Cu}$ during cooling after hot rolling. The mechanisms of the $\mathrm{Cu}$ addition induced grain-refinement are (1) suppression of austenite-ferrite transformation by the solute $\mathrm{Cu}$ in austenite which suppression prevents ferrite grain growth, (2) retardation of the recrystallization of hot deformed austenite by the solute $\mathrm{Cu}$ which retardation enhances ferrite nucleation.

The relationship between the yield strength and the ferrite grain diameter is shown in Fig. 2 by the form of the Hall-Petch relationship. The obtained grainrefinement with increasing the $\mathrm{Cu}$ addition up to 1.7 mass $\%$ and applying the heavy reduction and rapid cooling is also indicated in Fig. 2. The Hall-Petch relationship applies also to the steels $\mathrm{M} 1$ and $\mathrm{M} 2$, as far as the ferrite grain diameter is concerned. However, the strengthening is mainly brought about by bainite transformation as the typical case shown in Fig. 3, and thereby raises the transition temperature.

\section{Yield Strength-Transition Temperature Relationship Based upon Dislocation Crack Model}

Brittle crack initiation has been modeled by Cottrell, in which model $n$ dislocations pile up at the junction between two slip planes to form the Lomer-Cottrell barrier and provide the dislocation crack under the applied stress $\sigma$ normal to the (001) plane. ${ }^{53}$

(1) Fracture Stress $\sigma_{\mathrm{c}}$

When the nucleated crack propagates, the surface 

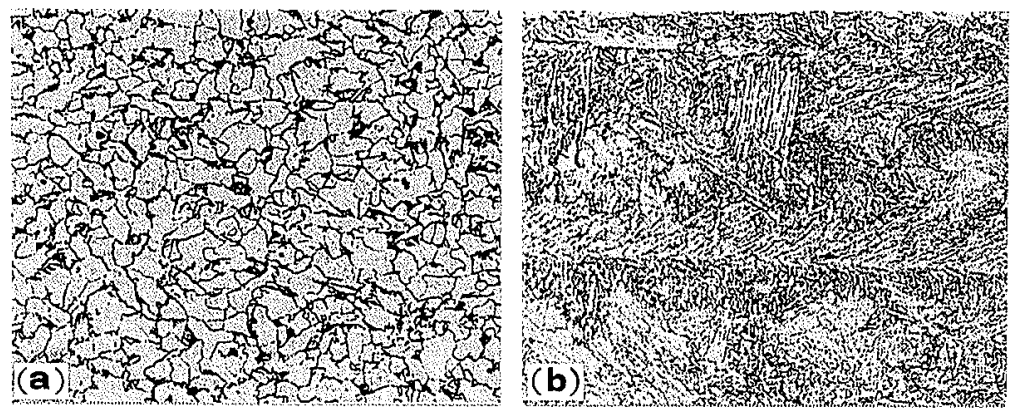

Fig. 3.

Increase in the fraction of bainitic microstructure with increasing the yield strength for steel M1.

(a) rolling code: $\mathrm{M1}-3$, yield strength: $358 \mathrm{MPa}$, vTrs: $-90^{\circ} \mathrm{C}$

(b) rolling code: M1-1, yield strength: $473 \mathrm{MPa}$, vTrs: $-50^{\circ} \mathrm{C}$ energy of the newly generated crack surface balances the work that the pile-up dislocations do overcoming the fracture stress. The energy balance condition gives:

$$
\sigma_{\mathrm{c}} n b=2 \gamma
$$

where $b$ is Burgers vector, $\gamma$ is surface free energy per unit area. The shear strain of grain caused by the pile-up dislocations is:

$$
\frac{n b}{d}
$$

where $d$ is grain diameter. Applying the Hooke's law and using the relationship between normal stress and shear stress, $\tau=\sigma / 2$, the shear strain is written:

$$
\frac{n b}{d}=\frac{\sigma_{\mathrm{e}}}{2 \mu}
$$

where $\mu$ is shear modulus and $\sigma_{\mathrm{e}}$ is effective stress to move the dislocations under applied stress. Here the Hall-Petch relationship is:

$$
\sigma_{\mathrm{y}}=\sigma_{0}+k_{\mathrm{y}} d^{-1 / 2}
$$

where $\sigma_{\mathrm{y}}$ is yield strength and $\sigma_{0}, k_{\mathrm{y}}$ are constants. The effective stress is:

$$
\sigma_{\mathrm{e}}=\sigma_{\mathrm{y}}-\sigma_{0}=k_{\mathrm{y}} d^{-1 / 2}
$$

From Eqs. (3), (4), (7), the fracture stress is written as a function of grain diameter. Thus,

$$
\sigma_{\mathrm{c}}=\frac{4 \mu \gamma}{k_{\mathrm{y}}} d^{-1 / 2}
$$

(2) Temperature Dependence of Yield Strength

The friction stress term of yield strength for ferrite consists of temperature independent stress $\sigma_{0}^{*}$ and temperature dependent stress $\sigma_{0}^{+}$:

$$
\sigma_{0}=\sigma_{0}^{*}+\sigma_{0}^{+} \text {. }
$$

The temperature dependence of $\sigma_{0}^{+}$is written:

$$
\sigma_{0}^{+}=c \exp (-\varepsilon T / c)
$$

where $c$ and $\varepsilon$ are constants, and $T$ is absolute temperature. To first order the temperature dependence is linear in $T$ :

$$
\sigma_{0}^{+}=c-\varepsilon T .
$$

Thus, the temperature dependence of yield strength is:

$$
\sigma_{\mathrm{y}}=\sigma_{0}^{*}+c-\varepsilon T+k_{\mathrm{y}} d^{-1 / 2} .
$$

$50 \mu \mathrm{m}$

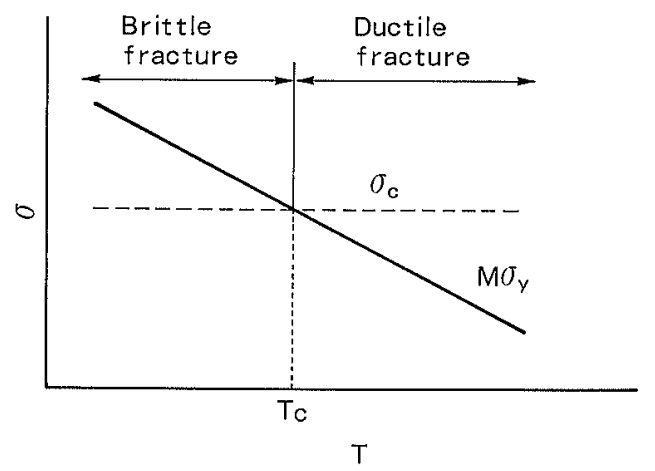

Fig. 4. Relationship between ductile-brittle transition and temperature dependence of yield strength. $M$ is stress concentration factor at the bottom of Charpy $\mathrm{V}$ notch.

(3) Relationship between Yield Strength and Transition Temperature

Supposing the ductile-brittle transition occurs when the fracture stress $\sigma_{c}$ is equal to $M \sigma_{y}$ as shown in Fig. 4 , the criteria of transition is:

$$
\sigma_{\mathrm{c}}=M \sigma_{\mathrm{y}}
$$

where $M$ is a geometry factor for stress concentration at notch bottom. From Eqs. (8), (12), (13), the criteria is:

$$
\frac{4 \mu \gamma}{M k_{\mathrm{y}}} d^{-1 / 2}=\sigma_{0}^{*}+c-\varepsilon T_{\mathrm{c}}+k_{\mathrm{y}} d^{-1 / 2}
$$

where $T_{\mathrm{c}}$ is transition temperature. Substituting $\sigma_{\mathrm{y}}$ for $\sigma_{0}^{*}, c$ and $k_{\mathrm{y}} d^{-1 / 2}$ deduces the relationship between yield strength and transition temperature:

$$
\varepsilon\left(T-T_{\mathrm{c}}\right)+\sigma_{y}=\frac{4 \mu \nu}{M k_{\mathrm{y}}} d^{-1 / 2} .
$$

The Equation (15) indicates that $T_{\mathrm{c}}$ rises with increasing $\sigma_{\mathrm{y}}$ at gradient $1 / \varepsilon$ if the grain diameter is constant, which relationship is illustrated in Fig. 5. The calculated gradient from the experimental results in this study is $0.46^{\circ} \mathrm{C} / \mathrm{MPa}$ of $1 / \varepsilon$.

(4) Effect of Grain-refinement on the Improvement of Yield Strength-Transition Temperature Balance

Substituting the Hall-Petch relationship in Eq. (15) eliminates $d$ :

$$
\varepsilon\left(T-T_{\mathrm{c}}\right)+\sigma_{\mathrm{y}}=\frac{4 \mu \gamma}{M k_{\mathrm{y}}^{2}}\left(\sigma_{\mathrm{y}}-\sigma_{0}\right) .
$$

Setting $4 \mu \gamma / M k_{\mathrm{y}}^{2}$ be $\Gamma$ : 


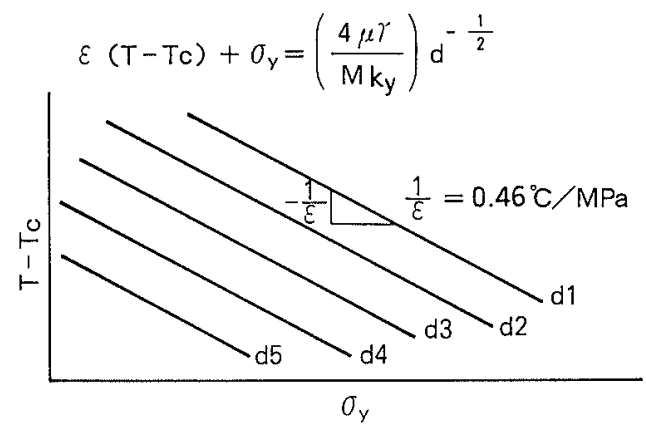

Fig. 5. Relationship between yield strength and Charpy V notch transition temperature at constant grain diameter.

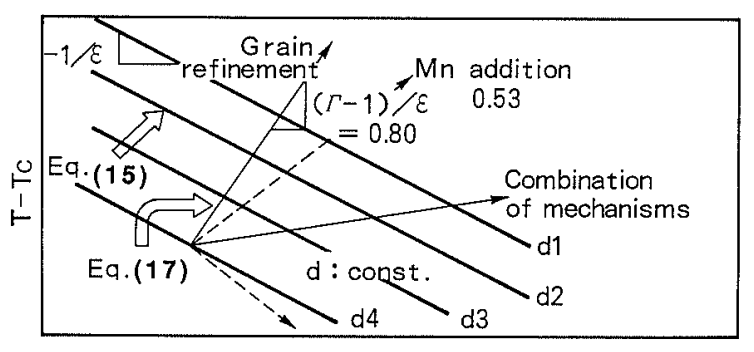

$\sigma_{\mathrm{y}}$

Fig. 6. Estimated improvement of yield strength-transition temperature balance by grain-refinement and the balance brought about by the combined strengthening with other mechanism.

$$
T-T_{\mathrm{c}}=\frac{\Gamma-1}{\varepsilon} \sigma_{\mathrm{y}}-\frac{\Gamma}{\varepsilon} \sigma_{0} .
$$

The Equation (17) includes $d$ implicitly, and indicates that the transition temperature $T_{\mathrm{c}}$ falls at the gradient of $(\Gamma-1) / \varepsilon$ with increasing $\sigma_{y}$ achieved by grain-refinement. Using the following substitutions in Eq. (17):

$$
\begin{aligned}
\mu & =\frac{E}{2(1+v)}=79200 \mathrm{MPa}, \\
E & =206000 \mathrm{MPa}, \\
\nu & =0.3 \\
\gamma & \left.=1.0 \times 10^{4} \mathrm{~J} / \mathrm{m}^{2}, 5,6\right) \\
M & =3,7) \\
k_{\mathrm{y}} & =19.6 \mathrm{MPa} \cdot \mathrm{mm}^{1 / 2},{ }^{8)}
\end{aligned}
$$

$(\Gamma-1) / \varepsilon=0.80^{\circ} \mathrm{C} / \mathrm{MPa}$ is obtained.

(5) Comparison with Experimental Results

Above argument is illustrated in Fig. 6. When the grain diameter $d$ is constant, the strengthening, which utilizes strengthening mechanisms except grain-refinement, raises the transition temperature linearly according to Eq. (15). The Equation (15) is consistent with the observed results about the precipitation-hardening of $\mathrm{Cu}$ and the bainite transformation-hardening in this study. On the other hand, the ideal strengthening which takes full advantage of grain-refinement obeys Eq. (17) and consequently improves the transition temperature with the estimated gradient of $0.80^{\circ} \mathrm{C} / \mathrm{MPa}$. When the strengthening utilizes other mechanisms combined with grain-refinement, the gradient will decrease. For instance,

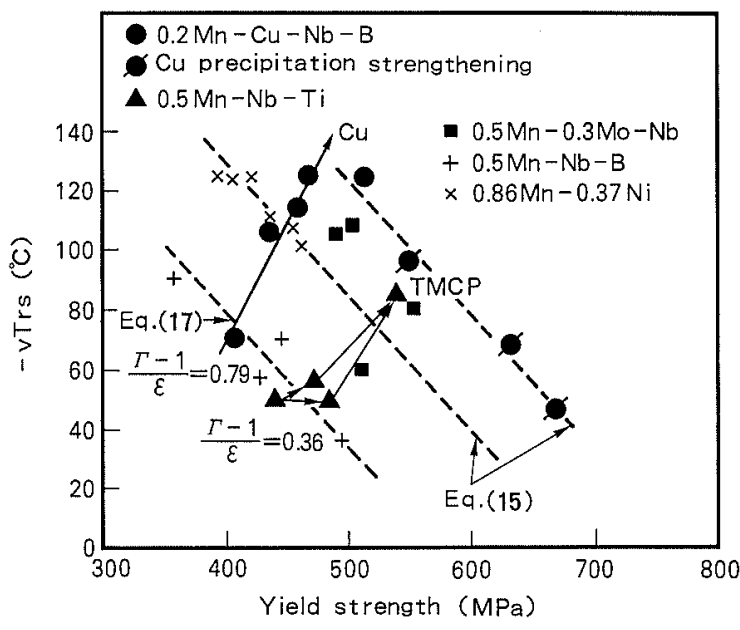

Fig. 7. Comparison between the predicted yield strengthtransition temperature balance and the empirically obtained balances by solute $\mathrm{Cu}$ and TMCP.

the $\mathrm{Mn}$ addition which brings about the grain-refinement combined with bainite transformation indicates the gradient of $0.53 .^{4)}$

Evaluating the effect of strengthening in this study as shown in Fig. 7, the strengthening and toughening achieved by solute $\mathrm{Cu}$ provides the gradient of $0.79^{\circ} \mathrm{C} /$ $\mathrm{MPa}$, which is in good agreement with the gradient estimated from the model. The grain-refinement is, thus, efficiently utilized in the strengthening mechanism of solute $\mathrm{Cu}$.

\section{Summary}

The yield strength-transition temperature relationship was investigated among several strengthening mechanisms for steels. The considered mechanisms include the grain-refinement with $\mathrm{Cu}$ addition, that with thermomechanical control process, the precipitation-hardening of $\mathrm{Cu}$ and bainite transformation-hardening with alloying elements such as B, Mo, Ni. The transition temperature rises with strengthening by the precipitationhardening and the transformation-hardening, and the relationship is approximately linear with the gradient of $0.46^{\circ} \mathrm{C} / \mathrm{MPa}$ irrespective of mechanism. In contrast, the transition temperature lowers with strengthening by the solute $\mathrm{Cu}$ and the TMCP which mainly utilize the grain-refinement.

The yield strength-transition temperature relationship was derived from the dislocation crack model which had been proposed by Cottrell, and compared with experimental results. The fracture stress is deduced by the energy balance when the nucleated crack by pile-up dislocations propagates to form new crack surface. Considering the temperature dependence of the friction stress provides the temperature dependence of yield strength in the form of the Hall-Petch relationship. As temperature decreases to the transition temperature, the yield strength increases accordingly. Assuming that the ductile-brittle transition occurs when the yield strength multiplied by the geometry factor of notch bottom reaches the fracture stress gives the relationship between the yield strength and the transition temperature. As 
far as the grain-diameter is constant, the transition temperature linearly rises with increasing yield strength, which relationship is consistent with the experimental results. When the yield strength is increased by grainrefinement, the transition temperature lowers linearly. The gradient is estimated approximately $0.80^{\circ} \mathrm{C} / \mathrm{MPa}$ and in good agreement with the experimental result for the strengthening and toughening by solute $\mathrm{Cu}$.

\section{REFERENCES}

1) N. J. Petch: J. Iron Steel Inst., 173 (1953), 25.

2) N. J. Petch: Philos. Mag., 3 (1958), 1089.

3) A. Takahashi and M. Iino: ISIJ Int., 36 (1996), 241.

4) A. Takahashi and M. Iino: ISIJ Int., 36 (1996), 235.

5) A. H. Cottrell: Trans. AIME, 212 (1958), 192.

6) J. Heslop and N. J. Petch: Philos. Mag., 3 (1958), 1128.

7) N. J. Petch: Fracture, Vol. 1, ed. by H. Liebowitz., Academic Press, New York, (1968), 381.

8) R. M. Fisher: Doctoral Thesis, Cambridge Univ., (1962). 